\title{
Procalcitonin - Influence of Temperature, Storage, Anticoagulation and Arterial or Venous Asservation of Blood Samples on Procalcitonin Concentrations
}

\author{
Michael Meisner ${ }^{1}$, Klaus Tschaikowsky ${ }^{I}$, Stephan Schnabel ${ }^{1}$, Joachim Schmidt ${ }^{1}$,Alexander Katalinic ${ }^{2}$ and \\ Jürgen Schüttler ${ }^{l}$ \\ ${ }^{1}$ Klinik für Anästhesiologie, \\ 2 Institut für Medizinische Statistik und Dokumentation, \\ Universität Erlangen-Nürnberg, Erlangen, Germany
}

\begin{abstract}
Summary: In this study we have analysed the influence of temperature and time of storage and of repeated freezing on procalcitonin plasma concentrations ex vivo. We have also analysed the difference of procalcitonin concentrations in arterial or venous blood samples and the influence of different anticoagulation techniques on procalcitonin concentrations (serum, EDTA-, lithium-heparin- or citrate plasma). At room temperature $\left(25^{\circ} \mathrm{C}\right.$ ) a loss of procalcitonin plasma concentrations of $6.4 \% \pm 2.6 \%$ (mean, 2 standard error of the mean) after 3 hours $\left(4.6 \% \pm 5.2 \%\right.$ at $\left.4{ }^{\circ} \mathrm{C}\right)$ and $12.3 \% \pm 3.1 \%$ after 24 hours occurred $\left(6.3 \% \pm 5.0 \%\right.$ at $4{ }^{\circ} \mathrm{C}, \mathrm{n}=17$ each). Comparing the procalcitonin concentrations of blood samples with different anticoagulants $(n=24$ each), there was only a significant difference between procalcitonin concentrations in heparinized plasma and serum ( $+7.6 \%$, difference of the mean). There was no significant influence of the blood sampling technique (arterial or venous line) and of repeated freezing/thawing cycles (up to 3 times) on the procalcitonin concentrations measured. Although the difference of sampling and storage of the blood on procalcitonin concentrations is not significant, multiple factors may act synergistically on the result of procalcitonin measurement. To keep variations of ex vivo conditions as minimal as possible, a standardized technique of anticoagulation, time and temperature of storage is recommended, e. g. the use of EDTA-plasma and storage at room temperature, when samples are measured within 4 hours after blood drawing.
\end{abstract}

\section{Introduction}

The pathophysiology of procalcitonin

Procalcitonin is a protein consisting of 116 amino acids (relative molecular mass about 13000) that is induced in high concentrations in severe bacterial infections, sepsis and multiple organ dysfunction syndrome. Viral infections, autoimmune disorders, allergic reactions, malignancies - apart from paraneoplastic production -, minor surgical procedures and local bacterial infections do not induce procalcitonin $(1-5)$.

Three groups of indications for procalcitonin measurement can be summarized:

1. differential diagnosis of severe bacterial infections from non-bacterial inflammation, e. g. viral versus bacterial meningitis, toxic versus biliary induced pancreatitis, bacterial versus non-bacterial etiology of acute respiratory distress syndrome;

2. infectious monitoring of severely ill patients, e. g. in multiple traumatized patients, after major surgical procedures, at patients under immunosuppression;
3. procalcitonin as prognostic marker and in the followup of patients with severe infections, sepsis and multiple organ dysfunction syndrome.

Except for immediate measurement in the acute disease, daily measurements are recommended for each patient. A kit for the determination of procalcitonin (PCT) is now commercially available (6). The "LUMItes ${ }^{\circledR}$-PCT" kit is an immunoluminometric assay. The reference limit of procalcitonin in healthy people is below $0.5 \mu \mathrm{g}^{-1}$, at sepsis and at severe inflammation concentrations of more than $1000 \mu \mathrm{g} \mathrm{l}^{-1}$ are reported $(3,4)$. Bacterial endotoxins are a main stimulus for the induction of procalcitonin $(7,8)$. Two to four hours after induction procalcitonin concentrations rapidly rise and reach maximal concentrations within 8 to 24 hours. Procalcitonin's halflife time in vivo is about 24 hours. The origin of inflammatory induced procalcitonin is not known. Neuroendocrine cells of the lung, liver or the intestine are presently being discussed (2). 


\section{Aim of the study}

Procalcitonin has recently been introduced into the routine diagnosis of severely ill patients. Daily measurements are now established in numerous intensive care units of major hospitals. As reference laboratory we are often questioned about kind and time of storage of procalcitonin, anticogulation and arterial or venous blood sampling. According to general experience procalcitonin is a very stable protein, also at room temperature. However, at present, no publications about the stability of procalcitonin are available. Neither are data published about the measurement of procalcitonin in different anticoagulants used for routine blood drawing or in serum samples. According to the commercial provider of the "LUMItest ${ }^{\circledR}$-PCT"-kit, B.R.A.H.M.S.-Diagnostica, Berlin, Germany, procalcitonin measurement should be done within 4 hours after blood drawing (6). However, patients with sepsis and acute infections may have an increased proteolytic activity of their blood. This might enhance degradation of procalcitonin, especially at high concentrations of procalcitonin that indicates a maximal stimulation of the cellular and humoral immunologic response. On the other hand, blood samples from foreign hospitals sometimes are kept at room temperature for more than 4 hours by mailing before measurement. Thus we have analysed the stability of procalcitonin in the plasma of 17 patients of our intensive care unit with different concentrations of procalcitonin at room temperature and at $4{ }^{\circ} \mathrm{C}$ during a storage time of 0 to 24 hours. We have also frozen and thawed plasma samples three times $\left(-20^{\circ} \mathrm{C}\right)$ to analyse changes caused by repeated freezing and thawing.

Further we have measured arterial and venous blood samples drawn simultaneously, since blood is sometimes drawn from either an arterial or a venous line.

The anticoagulation used may influence the measurement of some analytes. Since procalcitonin is a new analyte, we often get samples of either serum or plasma treated with different anticoagulants from foreign hospitals. To investigate the influence of anticoagulants, we have measured procalcitonin plasma concentrations in blood samples drawn in syringes containing different commercially available anticoagulants. Blood was drawn from procalcitonin-positive patients using simultaneously serum-monovettes, lithium-heparinized, EDTA-, citrate-, and sodium fluoride-coated monovettes.

\section{Materials and Methods}

Procalcitonin was measured by the "LUMItest ${ }^{\circledR}$-PCT"-kit (B.R.A.H.M.S.-Diagnostica, Berlin, Germany) using the AutoCliniLumat LB 952 (Laboratorium Prof. Berthold, Wildbad, Germany) according to the instructions of the manual (6): briefly, $20 \mu \mathrm{l}$ of samples (serum or plasma), standards and control serum are incubated in the precoated test tube with $250 \mu \mathrm{l}$ of tracer solution each of the kit for 2 hours at room temperature on a horizontal rotator
( $300 \mathrm{~min}^{-1}$, darkness). The test tube is coated with a monoclonal antibody specific for katacalcin. The tracer consists of an acridiniumbound anti-calcitonin monoclonal antibody and a stabilisation buffer. After incubation, the test tube is thoroughly rinsed three times using the washing solution (LUMItest ${ }^{\circledR}$-Washkit) and then dried upside down for 10 minutes on a soft tissue. The dried test tubes are measured in the luminometer according to the test guidelines (e. g. 2 blanks, 6 standards, 2 controls, 2 patient samples each). For the measurement $\mathrm{NaOH}(0.25 \mathrm{~mol} / \mathrm{l})$ and subsequent $\mathrm{H}_{2} \mathrm{O}_{2}\left(5 \mathrm{~g} / 1 \mathrm{H}_{2} \mathrm{O}_{2}\right.$ in $0.1 \mathrm{~mol} / 1 \mathrm{HNO}_{3}$ ) is automatically injected into the tubes by the double injector of the luminometer. The chemical reaction generates a short emission of light and is measured as "relative light unit" (RLU). Using the standards (concentration of 0.08, 0.5, 2.0, 20, 200, $500 \mu \mathrm{g} \mathrm{l}^{-1}$ procalcitonin) the actual concentration of the control- and patient samples is calculated automatically by a spline algorithm $(3,4,6)$ and the results are printed immediately. The entire procedure of measurement takes about $21 / 2$ hours.

Stability of procalcitonin at room temperature $\left(25^{\circ} \mathrm{C}\right)$ and $4{ }^{\circ} \mathrm{C}$ in plasma

Blood samples were drawn from 17 patients with increased procalcitonin concentrations (diagnosis: sepsis, severe bacterial infection, postoperatively increased procalcitonin concentrations) via an arterial catheter. For anticoagulation a $10 \mathrm{ml}$ EDTA-monovette (Sarstedt Nr. 02.1063) was used. The blood was centrifuged (10 min, $600 \mathrm{~g}, 4^{\circ} \mathrm{C}$ ) within 5 minutes after drawing and the sample of timepoint 0 (control) was frozen immediately $\left(-20^{\circ} \mathrm{C}\right.$ ). The other plasma was distributed into $1.5 \mathrm{ml}$ closed cups of polypropylene (Eppendorf, Germany) and was stored either at $25^{\circ} \mathrm{C}$ or at $4{ }^{\circ} \mathrm{C}$. At different times $(t=1 \mathrm{~h}, 3 \mathrm{~h}, 6 \mathrm{~h}, 24 \mathrm{~h})$ the respective sample was also frozen $\left(-20^{\circ} \mathrm{C}\right)$. Then all samples were thawed and analyzed simultaneously by the AutoCliniLumat LB 952 as described above.

\section{Arterial and venous samples}

Arterial and venous blood was drawn from 12 patients by means of an EDTA-monovette (Sarstedt Nr. 03.1396) using both simultaneously, an arterial catheter and a central vena jugularis interna catheter. Prior to asservation of the sample $5 \mathrm{ml}$ blood were drawn and discarded from the arterial line, and $10 \mathrm{ml}$ from the venous catheter. Blood was centrifuged at $600 \mathrm{~g}$ for 5 minutes $\left(4^{\circ} \mathrm{C}\right)$ and plasma was stored at $-20^{\circ} \mathrm{C}$ for less than one week. Measurements were performed using one "LUMItest ${ }^{\circledR}$-PCT"-kit with simultaneous incubation for both arterial and venous samples.

Comparison of procalcitonin concentrations in serum and plasma with different anticoagulants: lithiumheparin, sodium fluoride, citrate and EDTA plasma

Blood was drawn from an arterial catheter in 24 patients, centrifuged and measured as described above. The following commercially available syringes were used:

\section{Serum:}

- $10 \mathrm{ml}$ monovette (containing clot-activating granulate, Sarstedt, Germany, Nr. 02.1063)

\section{Plasma:}

- lithium-heparin plasma (lithium-heparin, $12-30 \times 10^{3} \mathrm{IU}^{-1}$, Sarstedt Nr. 03.1628 and 05.1147.020), also used for blood gas analysis (05.1147.020).

- sodium fluoride plasma (Sarstedt Nr. 05.1073.001), also used for lactate measurement.

- citrate plasma (31.3 g/1 tri-sodium-citrate-2-hydrate; dilution: 9 $\mathrm{ml}$ blood and $1 \mathrm{ml}$ of citrate solution, Sarstedt Nr. 05.1071), normally used for measurement of coagulation constituents.

- EDTA plasma (potassium-EDTA, 1.2-2 $\mathrm{g}^{-1}$, Sarstedt Nr. 03.1396), used for peripheral blood counts and haematocrit measurement. 


\section{Repeated freezing and thawing}

Blood samples $(\mathrm{n}=8)$ were drawn with an EDTA-monovette (Sarstedt Nr. 03.1396) and centrifuged as described. The samples were aliquotted into $1.5 \mathrm{ml}$ polypropylene vials (Eppendorf). The controls (no freezing) were analysed by the AutoCliniLumat LB 952 immediately. The other samples were frozen up to three times (55 minutes at $-20^{\circ} \mathrm{C}, 5$ minutes in a water-bath at $25^{\circ} \mathrm{C}$ until thawing) and were analysed immediately after each thawing as described above.

\section{Statistics}

All samples were analysed as duplicate measurements calculating the arithmetical average. The mean and standard error of the mean (S. E. M.) were calculated for each group. For comparison of different treated samples of each patient the non-parametric Wilcoxontest for dependent samples was used for absolute procalcitonin concentrations (programme Statistica 4.5 for Windows). Statistical significance was assumed with $p<0.05$. To compare different treated samples independently from the absolute concentration of procalcitonin, each value of one group (reference group, e. g. the serum group) was defined as 100 percent and the respective values of the different treated group were expressed as percent of variance of the reference value. The mean and standard error of the mean (S. E. M.) was calculated.

\section{Results}

\section{Storage at $4{ }^{\circ} \mathrm{C}$ and $25^{\circ} \mathrm{C}$}

The degradation of procalcitonin in plasma can be described by a biphasic kinetic (fig. 1). After the first 3 hours after collection and storage at $25^{\circ} \mathrm{C} 6.4 \%$ (mean) of the original concentration are lost, that are about $2.1 \%$ per hour. During the following 3 hours only $2.1 \%$ of procalcitonin is degraded representing a decay of $0.7 \%$ per hour. In the following 18 hours only $0.21 \%$ per hour are lost (see fig. 1). This is a total degradation of $12.3 \%$ within 24 hours. Within the first hour after collection and storage at $4{ }^{\circ} \mathrm{C}$ of the sample concentrations were increased in $82 \%$ of the samples with an increase of $12.4 \%$ in average. After 6 hours, $101.9 \%$ of the initial concentration was measured (mean) and after a storage of 24 hours at $4{ }^{\circ} \mathrm{C}, 93.7 \%$ of the original concentration

Tab. 1 Effect of storage temperature on procalcitonin plasma concentrations. Decrease of procalcitonin concentrations (mean, EDTA plasma) in percent of control after storage at room temperature $\left(25^{\circ} \mathrm{C}\right)$ and $4{ }^{\circ} \mathrm{C}$ for high and low plasma concentrations of procalcitonin. Results are displayed as percent of controls (immedi-

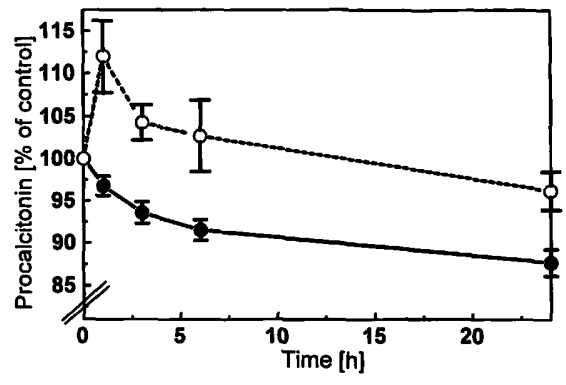

Fig. 1 Variations of procalcitonin plasma concentrations during storage at $25^{\circ} \mathrm{C}(\bullet)$ and $4{ }^{\circ} \mathrm{C}(0)($ EDTA plasma, $n=17$ samples each). Displayed are concentrations (mean) in percent of control $(t=0,100 \%)$ after storage of $1,3,6$ and 24 hours. Error-bars indicate standard error of the mean.

were found. The percentual decay was similar for high (procalcitonin $>8 \mu \mathrm{g}^{-1}$ ) and low (procalcitonin $<8 \mu \mathrm{g}^{-1}$ ) concentrations of procalcitonin both at $25^{\circ} \mathrm{C}$ and $4{ }^{\circ} \mathrm{C}$ (tab. 1).

\section{Repeated freezing and thawing}

Repeated freezing and thawing did not significantly influcence procalcitonin plasma concentrations (tab. 2). The median of variance of three-times frozen samples $(n=8)$ differed only $1.6 \%$ from that of non-frozen controls $(\mathrm{p}=0.6$, Wilcoxon test).

\section{Arterial and venous blood samples}

Arterial procalcitonin concentrations did neither significantly differ from venous plasma concentrations $(\mathrm{p}=0.239$, Wilcoxon test for dependent samples, $\mathrm{n}=12$ ), although procalcitonin concentrations were $4.1 \%$ higher (mean) in the arterial samples (tab. 3).

\section{Serum and plasma with different anticoagulants}

Comparing the procalcitonin concentrations of blood samples with different anticoagulants $(n=24$ each),

ate measurement, $\mathrm{t}=0$ ) for plasma samples with high $\left(>8 \mu \mathrm{g} \mathrm{1^{-1 }}\right.$ procalcitonin, mean $28.9 \mu \mathrm{g} \mathrm{l}^{-1}$ procalcitonin, $\mathrm{n}=8$ ) and low $(>8$ $\mu \mathrm{g} \mathrm{I}^{-1}$ procalcitonin, mean $4.8 \mu \mathrm{g} \mathrm{I}^{-1}$ procalcitonin, $\mathrm{n}=9$ ) plasma concentrations of procalcitonin. S. E. M., standard error of the mean.

\section{Storage}

\begin{tabular}{ll}
\hline $\begin{array}{l}\text { Temperature } \\
{\left[{ }^{\circ} \mathrm{C}\right]}\end{array}$ & $\begin{array}{l}\text { Duration } \\
{[\mathrm{h}]}\end{array}$ \\
\hline 25 & 1 \\
25 & 3 \\
25 & 6 \\
25 & 24 \\
4 & \\
4 & 1 \\
4 & 3 \\
4 & 6 \\
\hline
\end{tabular}

Plasma procalcitonin recovery [\% of control]

High concentrations $(n=8)$

Mean S.E.M.

95.4

93.3

90.3

88.0

116.8

107.0

104.0

94.9
Low concentrations $(\mathrm{n}=9)$

Mean S.E.M.

$\begin{array}{rl}97.6 & 1.1 \\ 93.8 & 1.4 \\ 92.1 & 1.6 \\ 87.5 & 1.9 \\ & \\ 105.2 & 5.6 \\ 100.7 & 4.2 \\ 98.5 & 3.0 \\ 93.3 & 3.4\end{array}$


Tab. 2 Effect of freeze-thawing on procalcitonin plasma concentrations. Procalcitonin plasma concentrations (mean, EDTA plasma) of frozen samples ( $n=8$, repeatedly frozen 1 to 3 times) in percent of fresh plasma. S. E. M., standard error of the mean.

\begin{tabular}{llll}
\hline $\begin{array}{l}\text { Freeze- } \\
\text { thawing }\end{array}$ & $\begin{array}{l}\text { Plasma procalcitonin } \\
\text { recovery }(\mathrm{n}=8) \\
{[\% \text { of control] }}\end{array}$ & S. E. M. & $\begin{array}{l}\mathrm{p} \\
\text { (Wilcoxon- } \\
\text { test) }\end{array}$ \\
\hline $1 \times$ & 101 & 2.64 & 0.249 \\
$2 \times$ & 98.9 & 1.91 & 0.600 \\
$3 \times$ & 101.6 & 2.08 & 0.600 \\
\hline
\end{tabular}

Tab. 3 Influence of anticoagulants and sampling site on procalcitonin concentrations. Procalcitonin concentrations (mean) in plasma containing different anticoagulants $(n=24$ each) in percent of serum concentrations. In addition, procalcitonin plasma concentrations in blood obtained from an arterial line (EDTA plasma) are presented in percent of procalcitonin plasma concentrations, measured in venous plasma. S. E. M., standard error of the mean.

\begin{tabular}{|c|c|c|c|}
\hline Specimen & $\begin{array}{l}\text { Procalcitonin } \\
{[\% \text { of control] }} \\
\text { Mean }\end{array}$ & S. E. M. & $\begin{array}{l}\mathrm{p} \\
\text { (Wilcoxon- } \\
\text { test) }\end{array}$ \\
\hline $\begin{array}{l}\text { Serum } \\
\text { (Control, } \mathrm{n}=24)\end{array}$ & 100 & & \\
\hline $\begin{array}{l}\text { Citrate plasma } \\
(\mathrm{n}=24)\end{array}$ & 95.95 & 2.21 & 0.145 \\
\hline $\begin{array}{l}\text { EDTA plasma } \\
(\mathrm{n}=24)\end{array}$ & 100.33 & 1.54 & 0.932 \\
\hline $\begin{array}{l}\text { Lithium-heparin } \\
\text { plasma }(n=24)\end{array}$ & 107.60 & 1.93 & 0.004 \\
\hline $\begin{array}{l}\text { Sodium fluoride } \\
\text { plasma }(\mathrm{n}=24)\end{array}$ & 104.38 & 2.18 & 0.052 \\
\hline $\begin{array}{l}\text { Venous EDTA } \\
\text { plasma } \\
\text { (control, } n=12 \text { ) }\end{array}$ & 100 & & \\
\hline $\begin{array}{l}\text { Arterial EDTA } \\
\text { plasma }(\mathrm{n}=12)\end{array}$ & 104.09 & 0.90 & 0.239 \\
\hline
\end{tabular}

there was only a significant difference between procalcitonin concentrations in heparinized plasma and serum. Using serum concentrations as a reference, concentrations of plasma procalcitonin differed $+7.6 \%$ for lithium-heparinized plasma $(p=0.004$, Wilcoxon test for dependent samples), $+4.38 \%$ for sodium fluoride plasma $(p=0.052),-4.05 \%$ for citrate plasma $(p=$ $0.145)$ and $+0.33 \%$ for EDTA-plasma $(p=0.932)$. Assessing procalcitonin concentrations of citrate plasma, a $9+1$ dilution from the citrate solution of the monovette should be considered. The comparison of the procalcitonin measurements in plasma samples with different anticoagulants or serum is shown in table 3 .

\section{Discussion}

Procalcitonin ex vivo is a very stable protein even at room temperature. Also repeated freezing and thawing does not significantly influence procalcitonin plasma concentrations. Arterial and venous samples do not differ in their concentrations of procalcitonin. Comparing procalcitonin concentrations in plasma samples containing different types of anticoagulants with procalcitonin in serum, a significant difference was only observed for lithium-heparinized plasma. However, this difference is very small and less than $8 \%$ in the mean. Likewise, the loss of procalcitonin plasma concentrations due to storage at $25^{\circ} \mathrm{C}$ is low. Even after 24 hours of storage at room temperature, only $12.4 \%$ (mean) of the original concentration is lost, and $6.3 \%$ at $4{ }^{\circ} \mathrm{C}$. The decay of procalcitonin is maximal during the first hours $(2.13 \%$ per hour) after blood sampling and decreased after 6 hours $(0.21 \%$ per hour). In some patients however, the combined influence of different anticoagulants, the variance of the assay, differences of time and temperature of storage might have synergistic effects and lead to a mismeasurement of the actual plasma concentration. Thus, we recommend a standardized procedure for asservation, anticoagulation and storage of procalcitonin samples. Storage at room temperature is recommended, when the time interval between blood drawing and measurement of the samples is quite constant, e. g. in daily routine diagnostic. Since the decay of procalcitonin in plasma at room temperature follows a reproducible kinetic, the time interval from blood drawing to measurement should be kept constant. This is important, since maximum degradation occurs during the first hours after drawing of the blood. For major intervals of storage, or if constant intervals cannot be maintained, either freezing or storage of the sample at $0-4{ }^{\circ} \mathrm{C}$ is recommended. The increase of procalcitonin concentrations observed during the first hours after blood drawing at $4{ }^{\circ} \mathrm{C}$ storage cannot be explained sufficiently at present. From other analytes, comparable observations are known and called "fresh-plasma-effect". These effects are explained by absorption and release of the substance to plasma proteins. Another explanation would be a decay of the whole protein of procalcitonin into smaller fragments, which also have a very high affinity to the antibodies of the immunoluminometric assay. Based on the design of the assay, also smaller molecules than the whole molecule of procalcitonin react with the assay, e.g katacalcin-calcitonin fragment sequences. The biphasic kinetic of degradation might be also explained by a rapid decay of procalcitonin into smaller fragments, which is followed by a second or slow period of degradation of these fragments. At present, there are no further data available to answer this question.

In summary, procalcitonin, compared to other inflammation markers like cytokines, has the advantage of a great stability at different conditions of storage $(4,5,9)$. If a precision of about $\pm 20 \%$ of the actual concentration is considered sufficient, there is no need to follow special guidelines for blood asservation. However, a decrease 
in procalcitonin concentrations occurs regularly due to different time and temperature of storage and the use of different anticoagulants. These factors may synergistically influence the procalcitonin measurement. Thus, a standardized procedure for procalcitonin samples is recommended for clinical routine diagnosis and, especially, for the daily follow-up of patients. The use of one specific anticoagulant or a certain temperature of storage

\section{References}

1. Assicot M, Gendrel D, Carsin H, Raymond J, Guilbaud J, Bohuon C. High serum procalcitonin concentrations in patients with sepsis and infection. Lancet 1993; 341:515-8.

2. Becker KL, O'Neill WJ, Snider R, Nylen ES, Moore CF, Jeng $\mathrm{J}$, et al. Hyperprocalcitoninemia in inhalation burn injury: a response of the pulmonary neuroendocrine cell? Anat Rec 1993; 236:136-8.

3. Meisner M. PCT - Procalcitonin. Ein neuer, innovativer Infektionsparameter. Biochemische und klinische Aspekte. Berlin: B.R.A.H.M.S.-Diagnostica, 1996.

4. Meisner M. PCT, Procalcitonin - a new, innovative infection parameter. Berlin: B.R.A.H.M.S.-Diagnostica, 1996.

5. Meisner M, Tschaikowsky K, Beier W, Schüttler J. Procalcitonin (PCT) - ein neuer Parameter zur Diagnose und Verlaufskontrolle von bakteriellen Entzündungen und Sepsis. Anaesth Intensivmed 1996; 10 (37):529-39.

6. B.R.A.H.M.S.-Diagnostica GmbH. LUMItest PCT. Coated Tube System. Immunoluminometrischer Assay (ILMA) zur Bestimmung von PCT (Procalcitonin) in Humanserum und Plasma. Instruction manual. Berlin: B.R.A.H.M.S.-Diagnostica, 1996. cannot be generally recommended but should be defined in each hospital. In our institution, we decided to store samples at room temperature, since the risk of temperature inconsistancy is less than during refrigeration. Blood drawing and measurement of procalcitonin is done at the same time each day. We also use EDTAplasma, which is also recommended by the provider of the "LUMItest ${ }^{\boxplus}$-PCT"-kit.

7. Dandona P, Nix D, Wilson MF, Aljada A, Love J, Assicot M, Bohuon C. Procalcitonin increase after endotoxin injection in normal subjects. J Clin Endocrinol Metab 1994; 79:1605-8.

8. Petitjean S, Mackensen A, Engelhardt R, Bohuon C, Assicot $M$. Induction de la procalcitonine circulante après administration intraveneuse d'endotoxine chez l'homme. Acta Pharm Biol Clin 1994; 5:265-8.

9. Meisner M, Tschaikowsky K, Schmidt J, Schüttler J. Procalcitonin (PCT) - Indications for a new diagnostic parameter of severe bacterial infection and sepsis in transplantation, immunosuppression and cardiac assist devices. Cardiovasc Eng 1996; $1: 67-76$.

Received February 24/ May 12, 1997

Corresponding author: Dr. med. Michael Meisner, Klinik für Anästhesiologie, Universität Erlangen-Nürnberg, Krankenhausstr. 12, D-91054 Erlangen, Germany.

Fax: +49-9131-85 6147 
